\title{
UMA LEITURA SEMIÓTICA DE TESMOFORIANTES DE ARISTÓFANES A SEMIOTIC READING OF ARISTOPHANES' THESMOPHORIASUZAE
}

\author{
Elvis Freire da Silva \\ Universidade Federal do Ceará (UFC) \\ freireelvis@gmail.com \\ Francisco Gleiberson dos Santos Nogueira \\ Universidade Federal do Ceará (UFC) \\ herrnogueira@gmail.com
}

Resumo. 0 presente trabalho tem como objetivo analisar a estrutura da peça Tesmoforiantes (411 a. C.) do comediógrafo grego Aristófanes (447 a.C - 385 a. C.) à luz da semiótica greimasiana ou discursiva de origem francesa. Para isso, utilizaremos os estudos de Fiorin (2013) e Barros (2008), nos quais poderemos encontrar o modelo de análise que aplicaremos aqui, seguindo o percurso gerativo do sentido. Nosso trabalho, dessa forma, será dividido em três partes. Inicialmente, serão feitas algumas considerações sobre a comédia antiga e a obra em estudo. Na segunda parte, partiremos do nível fundamental do sentido para então estabelecermos as relações primordiais do texto, ligadas às oposições fundamentais que norteiam a obra de Aristófanes. Na terceira e última parte, nosso enfoque estará voltado para o nível narrativo, em que poderemos ver, com mais profundidade, o procedimento de cada uma das personagens e suas dimensões significativas dentro da obra. Além dos estudos semióticos, utilizaremos ainda as obras de Slater (2002), Pompeu (2011) e Sousa e Silva (1987), para a análise de outros elementos essenciais da peça. A partir deste artigo, podemos concluir que o teatro de Aristófanes é constituído por uma reflexão, ao mesmo tempo política e literária, do século $\mathrm{V}$ a. C. e que a análise semiótica se constitui como uma importante ferramenta epistemológica para a compreensão das estruturas e do sentido dessa obra.

Palavras-chave: Semiótica discursiva; Aristófanes; Comédia Antiga; Tesmoforiantes.

Abstract. The aim of this work is to analyze the structure of the play Thesmophoriazusae (411 BC), accomplished by the Greek comic playwright Aristophanes (447 BC - 385 BC), in light of the Greimasian semiotic theory aka French discursive semiotics. To achieve this purpose, we will base our analysis on the works done by Fiorin (2013) and Barros (2008), in which we can find the ideal analysis model to be applied here, following the generative path of meaning. In so doing, our work will be divided into three parts. Initially, some considerations will be made about the Ancient Comedy and the specific play which is the focus of this article. In the second part, we will start from the fundamental level of meaning and then establish the primordial relations within the text, linked to the fundamental oppositions that guide Aristophanes' works. In the third and final part, our focus will be on the narrative level, in which we can analyze more deeply the attitudes of each of the characters and their significant dimensions within the play. Besides the semiotic studies, we will also refer to the works of Slater (2002), Pompeu (2011) and Sousa e Silva (1987), as far as the analysis of other essential elements of the abovementioned play is concerned. This article allows us to conclude that Aristophanes' theatrical comedy is constituted by a both political and literary reflection of the 5th century BC, and that the semiotic analysis constitutes an important epistemological tool for the understanding of the structures and meaning of the above-mentioned play.

Keywords: Discursive semiotics; Aristophanes; Ancient Comedy; Thesmophoriazusae.

\section{Introdução}

Aristófanes é o maior representante da chamada Comédia Antiga grega que floresceu no século V a.C. Dentre as onze comédias que restaram, integralmente, de sua prolífica obra (que teria escrito mais de quarenta peças), Tesmoforiantes é talvez a mais 
representativa do estilo paródico e da crítica literária aristofânica. No entanto, apesar de os elementos metaliterários serem centrais na obra, o seu momento de encenação (411 a.C., durante as Grandes Dionísias) é politicamente interessante para o entendimento desta peça.

Composta no mesmo ano de Lisístrata (apresentada nas Leneias), Tesmoforiantes é encenada em um momento de agitação política em Atenas e compartilha com a primeira uma característica singular: as mulheres como protagonistas. Boa parte da obra de Aristófanes foi escrita durante a guerra do Peloponeso, que acometeu Atenas entre os anos de 431 e 404 a.C. Em 411 a.C., temos a instituição do governo dos 400, de curta duração, e a primeira revolução oligárquica. Ao contrário do que fez em outras peças, Aristófanes não citará nomes de importantes políticos, como fazia com Cléon (duramente atacado em Vespas, por exemplo). O clima é de medo e instabilidade, especialmente para o poeta, que tem a tarefa de criticar a forma com que a cidade é regida. A guerra será para Aristófanes o grande problema para a pólis.

Desde Acarnenses, a comédia mais antiga que chegou até nós, já se tem exemplos do discurso antibélico ${ }^{1}$ de Aristófanes, que cria um personagem chamado Diceópolis ("cidade justa"), metáfora da própria pólis ateniense, que toma a paz somente para si. Em Lisístrata, temos uma greve liderada pelas mulheres, que querem os seus maridos de volta da guerra e para isso resolvem abdicar do sexo. Aqui, temos um embate entre o masculino e o feminino (representado no ágon entre os dois semicoros, formado por mulheres e velhos) pela acrópole de Atenas, centro do poder político da cidade.

Em Tesmoforiantes, há não só o embate, mas a simbiose entre os gêneros. Nesta peça, o personagem Eurípides e seu parente Mnesícolo procuram se infiltrar no Tesmofórion, onde as mulheres celebravam as Tesmofórias, festival em honra às deusas da terra e proibido aos homens. Eurípides, poeta trágico famoso por suas personagens femininas, é acusado pelas mulheres de criar um retrato maldoso do sexo feminino, sendo assim o responsável pela desconfiança de seus maridos. Com medo de ser assassinado pelas mulheres, Eurípides procura Agatão, também poeta trágico, para que o ajudasse infiltrando-se no Tesmofórion, onde jamais seria reconhecido como homem, já que era tão efeminado. 0 poeta se nega a invadir a reunião por não querer entrar em atrito com as mulheres, mas ajuda Mnesícolo a se vestir como uma mulher. Vestido com

\footnotetext{
${ }^{1}$ Sobre o discurso aristofânico, conferir Sousa e Silva (1987).
} 
as roupas de Agatão, o parente de Eurípides entra como uma velha no Tesmofórion, onde escuta as queixas das mulheres contra Eurípides, que as acusa de bêbadas e adúlteras. 0 parente argumenta que o poeta poderia ter ido ainda mais longe, enumerando suas inúmeras artimanhas, o que acaba por enfurecer as mulheres. Clístenes, um efeminado que aparece também em Lisístrata, entra no Tesmofórion para avisar que um aliado de Eurípides havia invadido o templo disfarçado. Depois de investigá-lo, o parente é finalmente despido e descoberto. Preso e vigiado por uma mulher enquanto as outras chamam o guarda, o parente decide então utilizar-se de uma série de artifícios teatrais, retirados das peças de Eurípides, para conseguir escapar.

Seguem-se então várias paródias, desde Palamedes, passando por Helena e Andrômeda, tragédias em que há cenas de resgate, assumindo o parente o papel feminino de Helena e Andrômeda, e Eurípides o de Menelau e Perseu. Apesar das encenações, nenhuma delas convence o guarda que vigia o parente. Eurípides desiste do plano, resolve se apresentar sem disfarces e propõe às mulheres não mais falar mal do sexo feminino se deixarem seu parente escapar. Caso não aceitem, ele divulgará aos maridos o que elas faziam enquanto eles estavam fora, em guerra. Convencidas as mulheres, resta o guarda, que é enganado por Eurípides vestido de velha, que traz uma bailarina para distrair o guarda, enquanto ele liberta o seu parente. Os dois fogem e a peça termina com o guarda procurando o prisioneiro, seguindo falsas indicações do coro.

As inúmeras paródias e recursos utilizados nessa comédia, exemplar da estética de Aristófanes, tornam esta peça uma obra extremamente complexa em termos ficcionais, estabelecendo uma série de níveis de realidade ${ }^{2}$. Nossa análise procura, dessa forma, focar-se nesses recursos e observar como Aristófanes articula os polos entre realidade e ficção.

Ainda que a comédia grega, cujo representante principal foi Aristófanes, tenha sido objeto de análises e estudos nos mais diversos âmbitos, não encontramos, na literatura, referência a uma análise dessa peça aristofânica sob a luz da semiótica discursiva. Esse trabalho apresenta-se então como uma proposta de análise, mostrando que também uma comédia grega clássica já se compunha, discursivamente, dos elementos que seriam tratados por Greimas na segunda década do século XX. 


\section{Nível Fundamental}

Como norte deste trabalho, partiremos agora para a análise de Tesmoforiantes à luz da semiótica greimasiana, objetivando identificar quais as ferramentas utilizadas no texto em questão para perseguir a construção do sentido ou, mais especificamente, o percurso gerativo do sentido. Salienta-se que não almejamos aqui esgotar todas as possibilidades de aplicação de uma teoria tão rica, mas sim propor uma análise dos pontos da peça per se, distanciando-nos um pouco de análises pautadas num viés mais sociológico e/ou histórico, depositando, no texto e nos elementos nele contidos, a chave para entendê-lo.

A semiótica greimasiana (GREIMAS; COURTÈS, 2011, p.234 ) considera o sentido de um texto como um percurso gerativo que é descrito em um processo que se desenvolve em diferentes níveis, contento, cada um deles, uma dimensão no âmbito sintático e outra no semântico. Desse modo, há desde um nível mais abstrato, o mais profundo (ou fundamental), até um mais concreto e figurativizado, o nível discursivo. Entre o nível fundamental e o discursivo, há o nível narrativo.

Grosso modo, no nível fundamental, encontram-se as estruturas semânticas fundamentais para a construção do sentido do texto. Como será exemplificado, tais estruturas semânticas estão em oposição do tipo X versus $\mathrm{Y}$, e, nessa relação, um dos elementos recebe o valor eufórico, enquanto o outro, o disfórico (FIORIN, 2013).

Do ponto de vista sintático, o que há nesse nível é presença de duas operações fundamentais: asserção e negação (GREIMAS; COURTÉS, 2011, p.474). No nível de nível fundamental, um texto pode apresentar, como reza a teoria, a seguinte estrutura (ou seu inverso): afirmação de $\mathrm{X} \rightarrow$ negação de $\mathrm{X} \rightarrow$ afirmação de $\mathrm{Y}$.

A partir da análise da peça, podem-se depreender algumas oposições semânticas que norteiam as ações das personagens e a utilização dos recursos cênicos, levando-nos a observar a afirmação de alguns objetos de valor e negação de outros. A primeira categoria que pudemos distinguir, e que está presente não somente nesta peça, mas em todas as comédias aristofânicas do século V a.C. é o par Guerra/ Paz. Essa categoria se expressa de diversas maneiras no texto, desde o nome das personagens (traço importante para o gênero cômico), até o embate do coro, o discurso apresentado na parábase, quando o coro se dirige ao público numa forma de representação da voz do poeta. Em Tesmoforiantes, peça em que o tema político está mais enviesado que em outras comédias, essa categoria se realiza na forma do conflito Masculino/Feminino. 
Na comédia de Aristófanes, as mulheres estão ligadas à paz, ao vinho, ao divertimento, enquanto os homens estão ligados à guerra, à batalha ${ }^{3}$. 0 gênero feminino é, de forma geral, ligado ao próprio gênero cômico, enquanto os homens representam o trágico. Em Tesmoforiantes, as mulheres que representam a cidade (reunidas em assembleia, como as mulheres de Lisístrata) decretam uma batalha contra o próprio poeta; querem tirá-lo a voz e evitar que ele continue a compor. Esse é um perigo que Aristófanes encarava enquanto realidade, dado o clima de pânico político por que passava Atenas nessa época. Em Lisístrata, peça estruturalmente semelhante à Tesmoforiantes, há uma assembleia para que se logre o fim da guerra contra Esparta, de modo que cidade possa voltar a copular e "ser feliz". A guerra é, desde o princípio, o objeto disfórico, e a paz, o eufórico, podendo esse processo ser assim resumido:

\begin{tabular}{|c|c|l|}
\hline (afirmação/disforia) & (negação/não disforia) & \multicolumn{1}{|c|}{ (afirmação/euforia) } \\
\hline Guerra & Não - Guerra & Paz \\
\hline Masculino & Não - Masculino & Feminino \\
\hline
\end{tabular}

\section{Tabela 1}

Seguindo essa sintaxe, podemos observar que o texto passa por transformações a partir de uma série de tensões (conflitos) que são resolvidos (relaxados), passando do termo disfórico (a guerra, o masculino) ao eufórico (a paz, o feminino). É importante observar como as categorias existem em relação de dependência: uma define a outra, mas não a exclui. Desse modo, guerra não elimina paz, mas se opõe a ela. 0 mesmo pode ser dito sobre o masculino e o feminino. Pensando na relação entre essas duas categorias, podemos enquadrá-las em um mesmo paradigma, organizando-as, assim, em um esquema lógico aqui representado na forma de um quadrado semiótico:

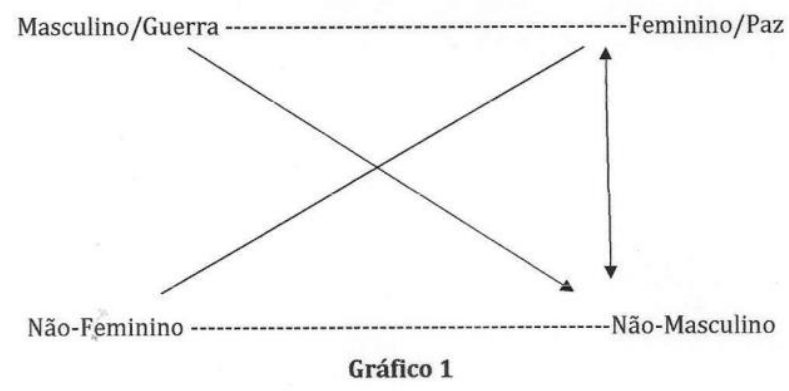

Cf. Pompeu (2011) 
Em que:

-- Termos contrários

- Termos contraditórios

$\leftrightarrow$ Operação de afirmação

$\rightarrow$ Operação de negação

No caso de Tesmoforiantes, poderíamos pensar ainda em outras relações no nível fundamental, no que concerne ao par Masculino/Feminino, que se sintetizam no hiperônimo Andrógino, o qual, na peça, aparece, em um primeiro nível, nas figuras dos efeminados Agatão e Clístenes, e, no segundo nível, em que levamos em conta a performance teatral, em todos os personagens femininos, que são interpretados por homens. Essa relação será abordada com mais vagar no nível narrativo.

\section{Nível narrativo}

Entre o nível fundamental e o discursivo propriamente dito, há um nível intermediário: o narrativo. Os valores descritos no nível fundamental tornam-se, no nível narrativo, objetos que passam a circular entre actantes. A análise nesse nível levará em consideração a ação dos sujeitos sobre tais objetos e, dessa forma, a ação das personagens e as suas consequências.

Já notamos no nível fundamental que o objeto valor buscado pelos sujeitos da peça é a paz. Cabe notar, nesse nível, quais as estratégias usadas por cada um dos sujeitos para entrar em conjunção com esse objeto eufórico, e a forma que ele toma individualmente. Faz-se necessário, portanto, observar cada um dos segmentos da peça, pensando sempre nos percursos do nível narrativo, isto é, a manipulação, a ação e a sanção.

No prólogo da peça, Eurípides e Mnesíloco batem na porta de Agatão, que os recebe cantando um hino feminino, fato que excita o Parente. Eurípides tenta então manipular Agatão para que este aceite disfarçar-se de mulher para agir em seu favor dentro do templo. Assim é que o destinador, Eurípides, procura seduzir Agatão (destinatário), que não aceita o contrato:

\section{Eurípides}

Eu te direi: primeiro, sou conhecido;

depois sou grisalho e tenho barba,
Destinador (Eurípides) Manipula (seduz) 
mas tu tens bela face, és branco, barbeado, tens voz de mulher, és delicado, belo de ver. (v.189-192)

\section{Agatão}

Não esperas agora que o teu mal nós suportemos. Pois seríamos loucos também. Mas suporta tu mesmo o que te é próprio. Pois não é justo suportar as desgraças com artifícios, mas passivamente. (v.195-200)

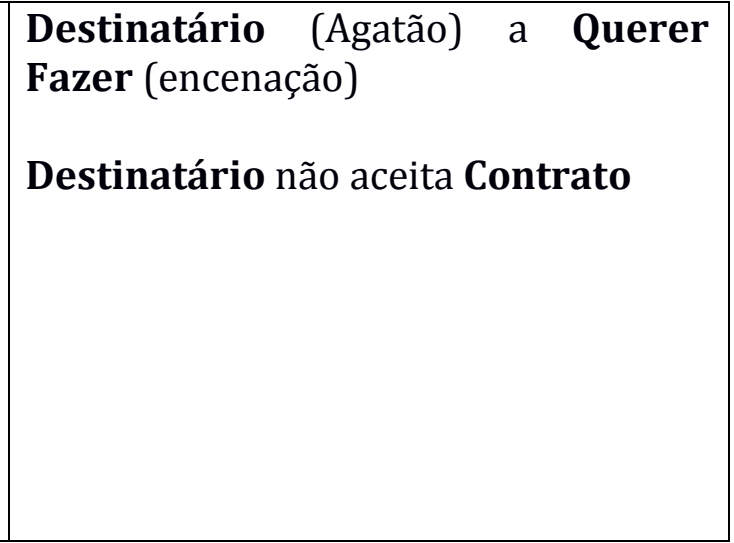

Tabela 2

A sanção é o desespero de Eurípides que se mantém sem poder entrar em conjunção com o objeto paz. 0 parente se compadece de Eurípides e resolve ele mesmo vestir-se como mulher e depilar-se. A cena da transformação do parente é simbólica da ilusão teatral. Partindo de a relação ser e parecer, todos os personagens femininos são, em um segundo nível de leitura, mentirosos. Isso porque são homens que fingem ser mulheres, os quais julgam outro homem que se finge de mulher. 0 parente vai ainda mais longe: é um homem que finge ser um homem, que por sua vez finge ser uma mulher. A performance é importante para entender a reflexão feita por Aristófanes sobre a natureza da ilusão teatral.

Já no Tesmofórion se inicia o argumento das mulheres, que não possuem o objeto paz e por isso desejam guerra contra Eurípides:

Mulher:
Pobre de mim, há muito tempo
suporto forçosamente ver que somos
ultrajadas por Eurípides, filho da
vendedora de legumes e ouvir muitas
maldades e de toda espécie. Pois, de
qual injúria ele não nos cobre? E
quando não nos calunia, por poucos
que sejam os espectadores, os atores
e coros, as levianas, as apaixonadas
por homens nos chama, as bebedoras
de vinho, as traidoras, as tagarelas, as
sem valor, a grande desgraça dos
maridos? De modo que logo que
saem do teatro olham-nos com
desconfiança e logo procuram se há
algum amante escondido em casa.
Mas não podemos mais fazer nada do
que fazíamos antes; tais foram as




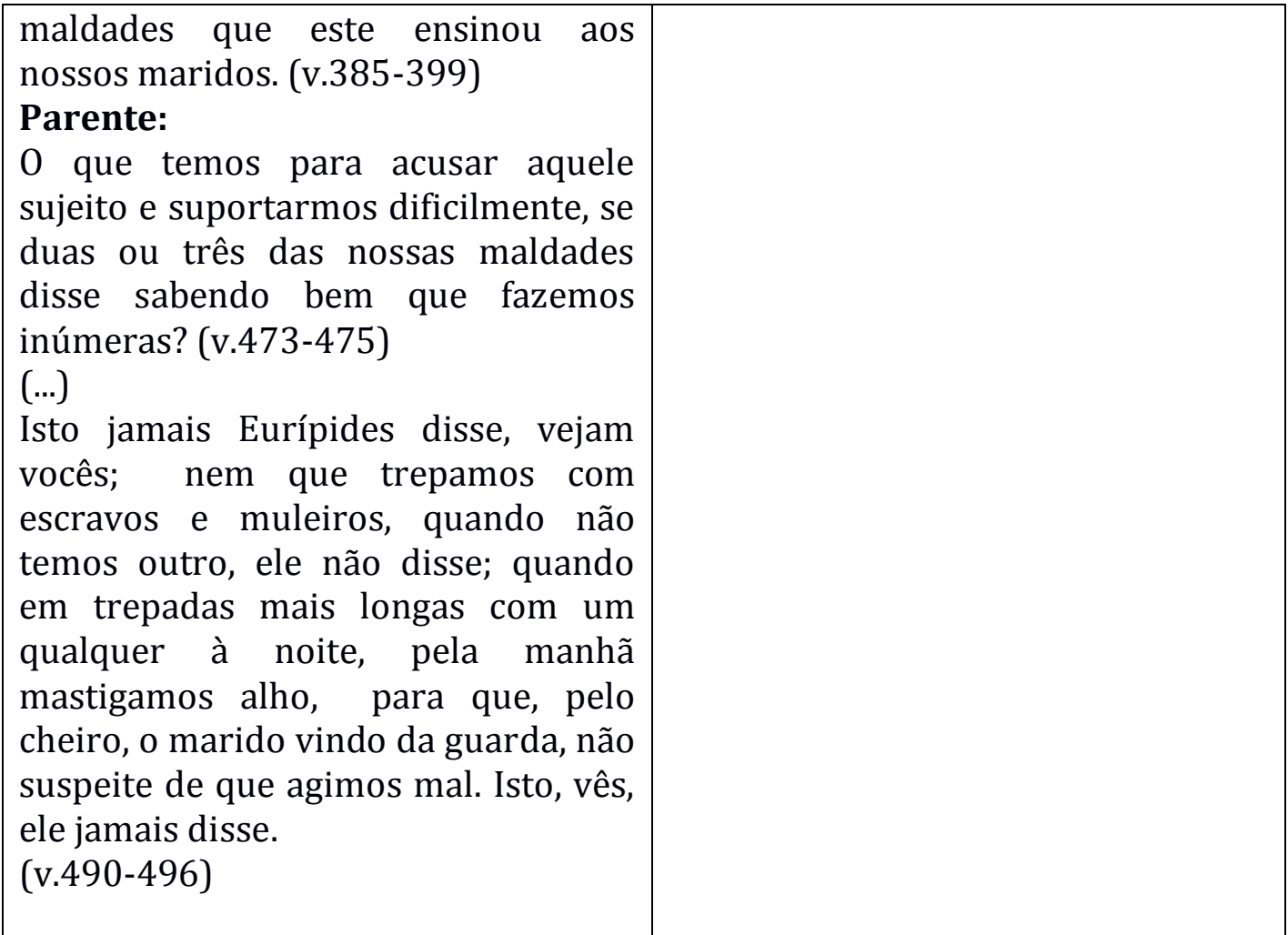

Tabela 3

As mulheres se irritam com as falas do parente, mas são interrompidas pela chegada de Clístenes, que as adverte sobre um espião. Depois de investigado e descoberta sua identidade, o parente toma como refém um bebê dos braços de uma mulher. A cena, que poderia ser trágica, se torna cômica ao notarmos que o bebê, na verdade, é um odre de vinho que a mulher trouxera para beber na reunião. A intimidação do parente para fazer com que as mulheres não o prendam acaba falhando. Tendo sido finalmente preso, o parente estabelece então uma nova estratégia de manipulação: o uso da própria ficção para iludir as mulheres.

Aqui é possível pensar na relação entre ser e parecer que permeia toda a peça. E, nesse ponto, pode-se recorrer ao quadrado veridictório de Greimas (GREIMAS; COURTÉS, 2011, p.532). Os valores apresentados pelo destinador (Eurípides/parente) são valores mentirosos (parecem e não são), já que são ficções (versões das peças de Eurípides). Nas três paródias apresentadas, Palamedes, Helena e Andrômeda, temos imagens de resgate, que no plano da realidade da peça se manifestariam no salvamento do parente por Eurípides. 0 contrato proposto pelo destinador, o fazer crer na liberdade do parente, não é aceito pela mulher que toma conta do parente ou pelo guarda. Eurípides, finalmente, propõe um novo contrato, definitivo, para as mulheres: 


\begin{tabular}{|c|c|}
\hline $\begin{array}{l}\text { Eurípides } \\
\text { Mulheres, se querem daqui para frente } \\
\text { fazer as pazes comigo, é agora, depois } \\
\text { disso não mais ouvirão de mim nada de } \\
\text { mal para o futuro. Eis o que proclamo. } \\
\text { Coro } \\
\text { E qual a necessidade de trazeres esta } \\
\text { proposta? } \\
\text { Eurípides } \\
\text { Este que está na tábua é meu parente. } \\
\text { Se eu o receber então, não ouvirão } \\
\text { jamais nada de mal; mas se não me } \\
\text { atenderem; o que agora ocultam aos } \\
\text { maridos eu vos delatarei ao virem das } \\
\text { expedições. } \\
\text { Coro } \\
\text { Sabe que sobre estas coisas } \\
\text { concordamos contigo; Mas convence tu } \\
\text { próprio este bárbaro. } \\
\text { (v.1160-1171) }\end{array}$ & $\begin{array}{l}\text { Destinador (Eurípides) Manipula } \\
\text { (intimida) } \\
\text { Destinatário (Mulheres) a Dever } \\
\text { Fazer (as pazes) } \\
\text { Destinatário (Mulheres) aceita o } \\
\text { Contrato (as pazes). }\end{array}$ \\
\hline
\end{tabular}

\section{Tabela 4}

Na cena final, o destinador (Eurípides) manipula (seduz) o destinatário (guarda) com o uso de uma dançarina para então obter o objeto (parente). A sanção se expressa ao fim da peça, em que os dois fogem e o guarda perde o objeto (parente). A paz se realiza de uma maneira diferente para os dois principais sujeitos da peça (Eurípides e mulheres), que compartilham desse mesmo objeto de valor.

Muitas são as relações que podem ser feitas a partir do texto de Aristófanes. Os jogos de linguagem, que podem ser mais bem explorados no nível discursivo, são ricos em artifícios linguisticamente interessantes para a compreensão da obra. A relação entre os gêneros cômico e trágico é outro tema que em Tesmoforiantes se expressa muito fortemente, especialmente na figura da personagem Eurípides. A análise semiótica possibilita, dessa forma, o entendimento das estruturas fundamentais que repercutem por todo o texto e a forma como os recursos críticos e metalinguísticos do poeta foram dispostos na ação das personagens e de suas consequências.

\section{REFERÊNCIAS}

ARISTÓFANES. Tesmoforiantes. Tradução, apresentação e notas Ana Maria César Pompeu. São Paulo: Via Leitura, 2015.

BARROS, Diana Luz Pessoa de. Estudos do discurso. In: Introdução a Linguística II: Princípios de Análise. José Luiz Fiorin (org.). São Paulo: Contexto, 2008. 
FIORIN, José Luiz. Elementos de análise do discurso. São Paulo: Contexto, 2013.

GREIMAS, A. J.; COURTÉS, J. Dicionário de Semiótica. São Paulo: Contexto, 2011.

POMPEU, Ana Maria César. Aristófanes e Platão: A Justiça na Pólis. São Paulo: Biblioteca 24horas, 2011.

SLATER, Niall W. Spectator Politics: metatheatre and performance in Aristophanes. Pennsylvania: University of Pennsylvania Press, 2002.

SOUSA E SILVA, Maria de Fátima. Crítica do teatro na comédia antiga. Coimbra: Instituto Nacional de Investigação Científica, 1987. 